\title{
Comparative Evaluation of Shear Bond Strength and Flexural Strength of New Zirconia Reinforced Glass lonomer Cement with Commonly used Glass Ionomer Cements Used in Atraumatic Restorative Treatment: An In Vitro Study
}

\author{
${ }^{1}$ Pritha Bhattacharya, ${ }^{2}$ Jaya Naidu, ${ }^{3}$ Pavan B Tambakad
}

\begin{abstract}
Objective: The objectives of the present study were to evaluate and compare the shear bond strength (SBS), and the flexural strength (FS) of zirconia reinforced glass ionomer (Zirconomer) and two conventional glass ionomer cements commonly used in atraumatic restorative treatment (ART).

Materials and methods: The bond sites for SBS testing were prepared on enamel $(n=45)$ and dentine $(n=45)$ on caries free, extracted human permanent molars. The specimens were randomly divided into six groups $(n=15)$ for each restorative material and site (dentine or enamel) tested. They were loaded in an Instron Universal Testing Machine (UTM) at a crosshead speed of $0.5 \mathrm{~mm} / \mathrm{min}$ for SBS and $1.0 \mathrm{~mm} / \mathrm{min}$ for the three-point FS test until failure occurred. Mode of failure was assessed using stereomicroscope $(10 \times)$.
\end{abstract}

Results: Ketac ${ }^{\mathrm{TM}}$ Molar (KM) demonstrated the highest mean SBS to enamel and significantly higher mean SBS to dentin in comparison with the other groups. Zirconomer and Fuji IX GP Extra (FJ) showed comparable SBS to enamel and dentin. KM also demonstrated significantly higher FS in comparison to the other groups.

Significance: Within the limitations of the present study, Zirconia reinforced glass ionomer cement (GIC) can be an alternative to conventional GICs for application in ART. However, further studies are required to prove its clinical performance in the clinical scenario.

Keywords: Atraumatic restorative treatment, Flexural strength, Glass ionomer cements, Shear bond strength, Stereomicroscope.

How to cite this article: Bhattacharya P, Naidu J, Tambakad PB. Comparative Evaluation of Shear Bond Strength and Flexural Strength of New Zirconia Reinforced Glass Ionomer Cement with Commonly used Glass Ionomer Cements Used in Atraumatic Restorative Treatment: An In Vitro Study. J Oper Dent Endod 2018;3(2):83-91.

Source of support: Nil

Conflict of interest: None

${ }^{1}$ Postgraduate Student, ${ }^{2}$ Professor and HOD, ${ }^{3}$ Former HOD

${ }^{1-3}$ Department of Pedodontics and Preventive Dentistry, Vydehi Institute of Dental Sciences and Research Centre, Bengaluru, Karnataka, India

Corresponding Author: Pritha Bhattacharya, Postgraduate Student, Department of Pedodontics and Preventive Dentistry, Vydehi Institute of Dental Sciences and Research Centre, Bengaluru, Karnataka, India, e-mail: prithabhatt16@gmail.com

\section{INTRODUCTION}

Atraumatic restorative treatment (ART) or approach makes the use of hand instruments to remove caries affected tooth structure. The prepared cavity is then restored with hand mixed traditional glass ionomer cement. Specially formulated glass ionomers (GI) with high powder liquid ratio and improved physical properties have been developed for ART. ${ }^{1}$ Conventional GI are plagued with deficient physical and mechanical properties and susceptibility to moisture contamination and dehydration during initial setting. In the last two decades, research and development has focused primarily on overcoming the disadvantages associated with the traditional $\mathrm{GI}^{2}{ }^{2}$ and specifically on the enhancement of the mechanical properties of GICs. Development in the field of material research has yielded novel GIC for ART. ${ }^{3}$

$\operatorname{Ketac}^{\mathrm{TM}}$ Molar (3M ESPE) is a glass ionomer with suitable properties for the clinical applications in ART. Ketac $^{\mathrm{TM}}$ Molar Easymix (KM) shows highly improved wettability of the powder by the liquid component that results in easy and fast mixing. This material is an easy to mix glass ionomer with high physicomechanical properties. ${ }^{4}$

Fuji type IX GIC (GC TOKYO) (FJ) also known as condensable or packable and high viscous GIC, possesses higher strength, greater wear resistance, and flexural strength as compared to conventional GICs. Type IX GIC (GC IX) is less sensitive to moisture and more resistant to dissolution when compared with conventional GIC. ${ }^{5}$

Recently, a novel biomaterial, zirconia-reinforced GI (Zirconomer, Shofu Inc., Japan), has been developed that overcomes the drawbacks of previously used tooth-color restorative materials, while combining and retaining the benefits of both amalgam and conventional GI. It has zirconium oxide, glass powder, tartaric acid ( 1 to $10 \%)$, polyacrylic acid (20-50\%), and deionized water. Zirconomer is reported to possess outstanding strength, durability, and offers sustained fluoride release. ${ }^{6}$

The clinical success of restorative materials depends upon good adhesion with tooth surfaces and resistance to various dislodging forces acting within the oral cavity. The SBS is 
described as the resistance to forces that slides restorative material past tooth structure. It is assumed to have greater clinical importance because the most dislodging forces at the tooth- restoration interface have a shearing effect. Therefore, high SBS dictates better bonding of the restorative material to tooth. ${ }^{5}$ While flexural strength (FS) values reflect a limited tendency for crazing and high resistance to surface defects and erosion. ${ }^{7}$

In light of the concerns associated with the strength and physical properties of restorative materials, which play a vital role in durability and resistance of the restoration to fracture due to occlusal load, and the paucity of research on the physicomechanical properties of Zirconia-reinforced GI (Zirconomer), an innovative dental material, the present study was undertaken to compare the shear bond strength (SBS) and flexural strength (FS) of Zirconomer with two conventional GICs for ART restorations.

\section{MATERIALS AND METHODS}

The dental materials used in the present study are listed in Table 1.

\section{Collection and Storage of Teeth}

Seventy non-carious therapeutically extracted permanent molar teeth were collected. After extraction, teeth were washed in running water and made free from blood and adherent tissues with an ultrasonic scaler. The teeth were examined to ensure that they fulfilled the following inclusion and exclusion criteria.

\section{Inclusion Criteria}

Intact, caries free, unrestored teeth were included in the study.

\section{Exclusion Criteria}

Teeth that were carious, hypoplastic and cracked were excluded from the study.

The selected teeth were stored in accordance with the International Standardization Organization (ISO) specification/TS 11 405:2015(E): ${ }^{8}$
The stored teeth were used for sample preparation and testing within 6 months of storage.

\section{Shear Bond Strength (SBS) Evaluation}

\section{Tooth Preparation}

The crowns of the collected teeth were separated from the roots at the cemento-enamel junction (CEJ) perpendicular to the long axis of the tooth, using a diamond-disk with water coolant. ${ }^{9,10}$

The bond sites were prepared either on enamel or dentin.

Enamel bond sites: The crown of the teeth were separated and sectioned into two halves: mesial and distal proximal using a low-speed diamond disk under continuous water-cooling. ${ }^{11}$

Dentin bond sites: The mid-coronal dentin of the occlusal surfaces was obtained by placing a flat cut perpendicular to the long axis of the tooth. ${ }^{12}$

The teeth were inspected for pulp exposure, and in case of pulp exposure, the teeth were discarded. ${ }^{11}$

Specimen grouping: The prepared specimens were randomly divided (Flow Chart 1 ) into six groups according to the material used and the bonding sites. Custom made cylindrical metallic mold of $20 \mathrm{~mm}$ length and $14 \mathrm{~mm}$ diameter was filled with auto-polymerizing acrylic resin. Each metallic mold consisted of an external cylindrical part surrounded by another split metallic component of $18 \mathrm{~mm}$ height/12 $\mathrm{mm}$ diameter. These two metallic components were adjusted together through two external screws to facilitate the insertion and removal of the acrylic block from the mold. ${ }^{11}$ Prepared tooth specimens were embedded horizontally in the acrylic resin. The experimental surface was kept free from contamination from acrylic resin. After setting of the acrylic resin, the specimens were removed from the mold and the occulsal (dentin bond site) or proximal (enamel bond site) surface of the crown, was gently ground with 220, 400 and 600 grit silicon carbide papers successively to obtain flat enamel or dentine

Table 1: List of materials used in the study

\begin{tabular}{|c|c|c|c|c|}
\hline Materials & Composition & $\begin{array}{l}\text { Material } \\
\text { description }\end{array}$ & Manufacturer & $\begin{array}{l}\text { Batch } \\
\text { number }\end{array}$ \\
\hline Zirconomer & $\begin{array}{l}\text { POWDER: Alumino-fluoro-silicate zirconium } \\
\text { oxide,tartaric acid. } \\
\text { LIQUID: Polyacrylic acid, deionized water. }\end{array}$ & $\begin{array}{l}\text { Zirconia } \\
\text { reinforced glass } \\
\text { ionomer. }\end{array}$ & $\begin{array}{l}\text { Shofu inc. Kyoto, } \\
\text { Japan }\end{array}$ & 01170482 \\
\hline $\begin{array}{l}\text { Ketac }^{\mathrm{TM}} \text { Molar } \\
\text { Glass Ionomer } \\
\text { Restorative material }\end{array}$ & $\begin{array}{l}\text { POWDER: Calcium, Lanthanum, Alumino- } \\
\text { fluorosilicate glass, Pigments. } \\
\text { LIQUID: Polycarbonic acid,Tartaric acid, water. }\end{array}$ & $\begin{array}{l}\text { Conventional Glass } \\
\text { Ionomer with High } \\
\text { viscosity. }\end{array}$ & 3M ESPE & 05K16S \\
\hline $\begin{array}{l}\text { Fuji IXGP extra (GC } \\
\text { Gold label } 9 \text { Extra) }\end{array}$ & $\begin{array}{l}\text { POWDER: Silica, Alumina,Aluminium } \\
\text { Fluoride, Calcium Fluoride, cryolite, } \\
\text { aluminium phosphate. } \\
\text { Liquid: Polyacrylic acid, Itaconic acid, tartaric acid, } \\
\text { maleic acid. }\end{array}$ & $\begin{array}{l}\text { Conventional Glass } \\
\text { Ionomer with } \\
\text { High viscosity. }\end{array}$ & GC America & $\begin{array}{l}1701071 \\
1703011\end{array}$ \\
\hline
\end{tabular}


Flow Chart 1: Overview of experimental design for shear bond strength testing

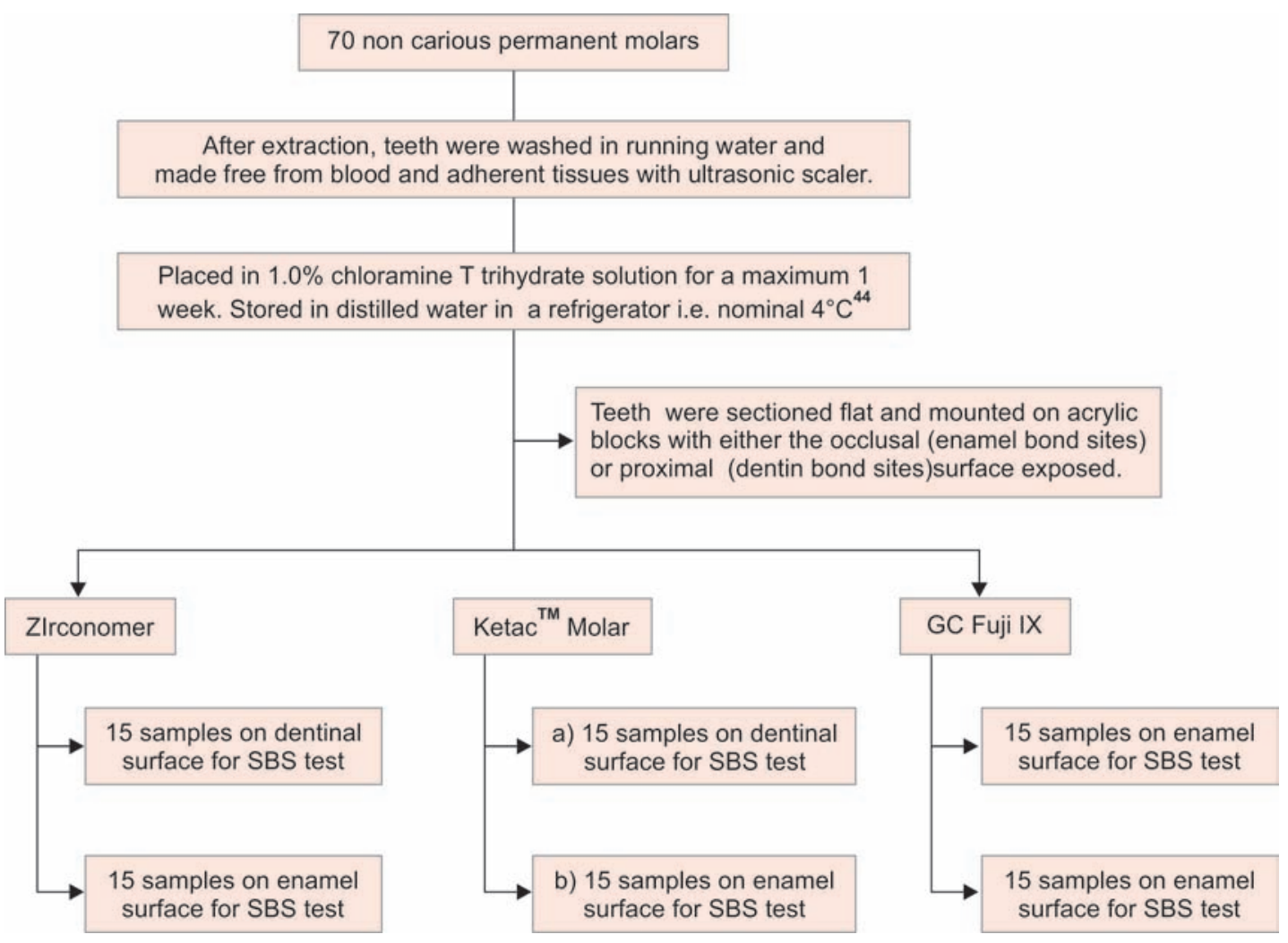

surfaces. ${ }^{11}$ The dentin and enamel bond surfaces were rinsed with copious water, and gently air dried. ${ }^{10} \mathrm{~A}$ specially designed custom made split Teflon mold $2.5 \mathrm{~mm}$ diameter $/ 2 \mathrm{~mm}$ height ${ }^{13}$ was secured to the polished, clean and dry flat enamel and dentine surface prior to application of the test materials. This Teflon mold was stabilized in its place by the mean of another split metallic ring fitted inside the external cylindrical metallic mold . ${ }^{11}$

The specimens for each group were prepared and applied according to the manufacturer's instructions.

- Preparations of samples: Petroleum jelly was slightly applied to the internal surface of the teflon mold to avoid bonding of GIC to the mold. The mold was cleaned between each bonding procedure and care was taken not to reuse the mold for a different material. The mold was placed in tight contact with the dentin or enamel bond sites for placement of the restorative material. ${ }^{10}$

The mixed cement was introduced into the teflon mold using plastic instruments ${ }^{9}$ and allowed to set for 10 minutes before separation from the mold. The specimens were then removed carefully, and a protective coating of Vaseline as recommended by the manufacturer was applied. Specimen Storage: Immediately after bonding, the specimens were immersed in distilled water in individual test tubes in an incubator at $37^{\circ} \mathrm{C}$ until testing. The investigator was blinded with regards to the test groups at this point to avoid bias during testing.
The SBS testing was conducted after a minimum storage period of 24 hours. The storage period did not exceed 7 days.

- Shear bond strength Test: The SBS tests were performed using Instron Universal Testing Machine with a crosshead speed of $0.5 \mathrm{~mm} /$ minute (Fig. 1). ${ }^{11}$

The SBS values were calculated by dividing the load at failure (Newton) by the area of the cylindrical cross-section $\left(4.90 \mathrm{~mm}^{2}\right)$, and expressed in megapascal (MPa). ${ }^{9,11}$

- Mode of Failure Evaluation: After testing for SBS, the fractured surface of each specimen was examined with an optical microscope (Stereomicroscope SR, Zesis, Germany) at a magnification of $10 x$ to determine the mode of failure. ${ }^{14}$

The mode of failure was classified as ${ }^{15}$ type A (adhesive failure at the interface), type $\mathrm{M}$ (mixed adhesive failure at the interface + cohesive in the restorative material), type $\mathrm{C}$ (cohesive in the restorative material).

The flexural bond strength (FS) evaluation: Preparations of samples and storage: The specimens for the FS test (Flow Chart 2) were prepared using a rectangular teflon mold with dimensions of $2 \mathrm{~mm}$ width by $2 \mathrm{~mm}$ depth by 25 mm length. ${ }^{16}$ The test materials were mixed according to the manufacturer's instructions, and the mixed cement were introduced into the customized Teflon mold using plastic instruments ${ }^{9}$ and allowed to set for 10 minutes before separation from the mold. Then the specimens were removed carefully. Specimens were stored in an incubator until testing, in individual test tubes. 


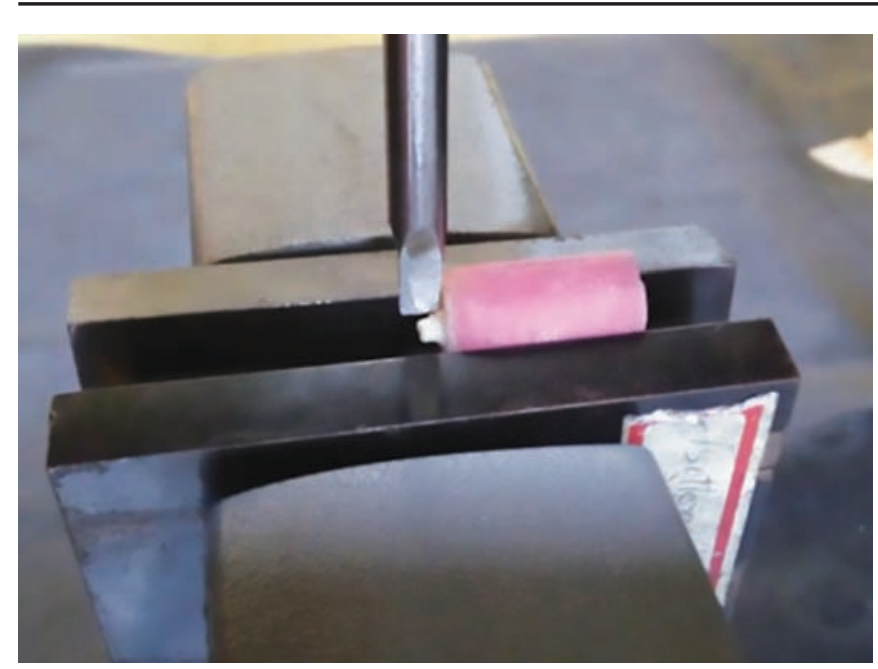

Fig. 1: SBS sample under load

Flow Chart 2: Overview of experimental design for flexural strength testing.

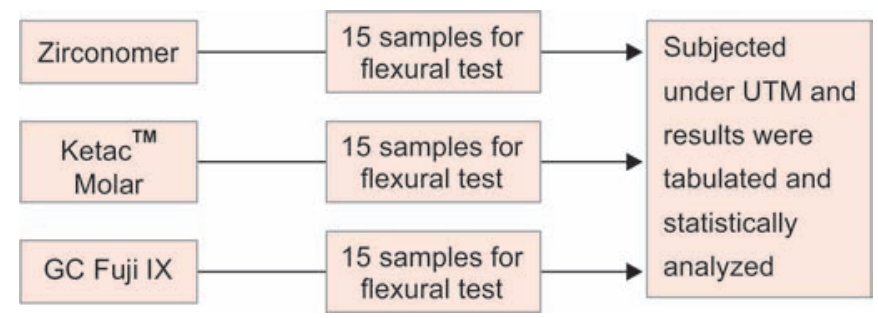

The investigator was blinded with regards to the test groups at this point to avoid bias during testing.

- Flexural strength Test: Specimens were subjected under the universal testing machine with a crosshead speed of $1 \mathrm{~mm} /$ minute (Fig. 2). Three-point FS was calculated according to the following formula in (MPa) (ISO 4049): FS $=3 \mathrm{~F} \mathrm{~L} /\left(2 \mathrm{~b} \mathrm{~d}^{2}\right)$, where $\mathrm{F}$ is the maximum force $(\mathrm{N}), \mathrm{L}$ is the distance between the layers $(\mathrm{mm}), \mathrm{b}$ is the width of the specimen ( $\mathrm{mm}$ ), and $\mathrm{h}$ is the height of the specimen $(\mathrm{mm}){ }^{17}$

\section{Statistical Analysis}

Results were tabulated and statistically analyzed using o)ne-way analysis of variance (ANOVA) with Turkey's Post hoc test and Chi-square test. Probability value .05 ( $p \geq 0.05$ ) was considered as significant.

\section{RESULTS}

TheKMdemonstrated thehighestmean shear bond strength to enamel $(6.07 \pm 0.50 \mathrm{MPa})$ which was, however, not significantly higher than the other two groups. Zirconomer $(5.86 \pm 0.50 \mathrm{MPa})$ and $\mathrm{FJ}(5.79 \pm 0.48 \mathrm{MPa})$ had the comparable shear bond strength to enamel (Tables 2 and 3).

The KM showed significantly higher mean shear bond strength to dentin $(7.43 \pm 0.69 \mathrm{MPa})$ in comparison with the other groups. Zirconomer $(6.43 \pm 0.41 \mathrm{MPa})$ and FJ $(6.04 \pm 0.32 \mathrm{MPa})$ had comparable shear bond strength to dentin (Tables 4 and 5).

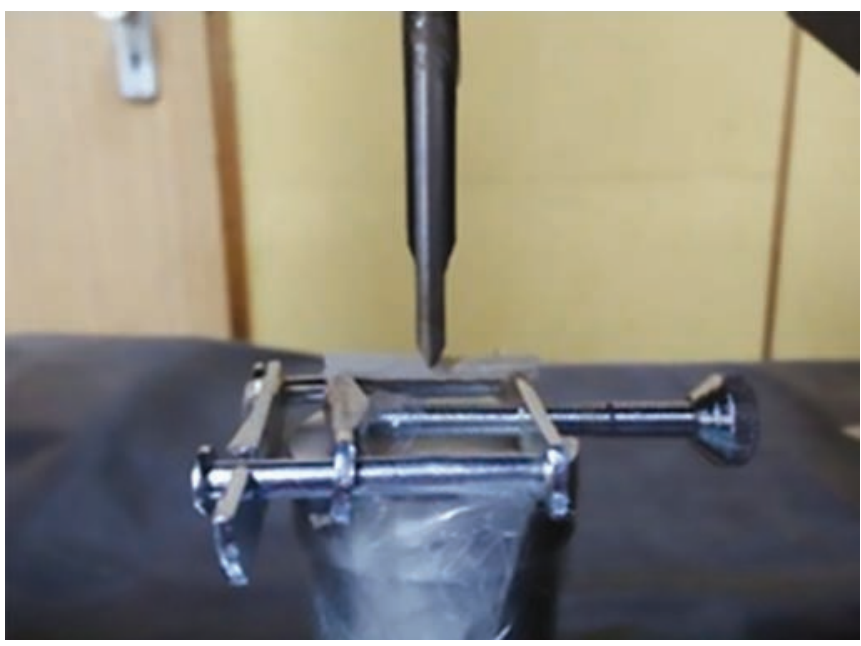

Fig. 2: FS sample under load

Mode of failure analysis showed the highest percentage of the adhesive mode of failure for the enamel surface/site for all the groups, with Zirconomer showing $66.7 \%$, KM 60.0\%, and FJ 66.7\% adhesive mode of failure. There was no significant difference in the results between the groups (Table 6).

For dentine bond surfaces/sites, mode of failure analysis showed the highest percentage of the cohesive mode of failure for Zirconomer (46.7\%), whereas KM $(60.0 \%)$ and FJ $(53.3 \%)$ had a greater percentage of an adhesive mode of failure.

Inter group comparison showed no statistically significant difference (Table 7).

Intragroup comparison of SBS for enamel and dentin bond surfaces for Zirconomer showed no significant difference, whereas, for KM the SBS was significantly higher for dentin bond surfaces $(7.43 \pm 0.69 \mathrm{MPa})$ when compared to enamel bond surfaces $(6.07 \pm 0.50 \mathrm{MPa})$. FJ also demonstrated significantly higher, bond strength for the dentin surfaces $(6.04 \pm 0.32 \mathrm{MPa})$ when compared to the enamel bond surfaces $(5.79 \pm 0.48 \mathrm{MPa})$. KM showed significantly higher FS $(62.68 \pm 13.59 \mathrm{MPa})$ followed by Zirconomer $(52.46 \pm 10.68 \mathrm{MPa})$ while the lowest FS value was found in $\mathrm{FJ}(46.73 \pm 6.77 \mathrm{MPa})$ (Table 8).

\section{DISCUSSION}

The ART is considered a minimal intervention approach. It employs the use of hand instruments to remove the softened carious enamel and dentin and to restore the cavity with an adhesive restorative material. Introduced to provide simple restorative care to young children, patients with special health care needs, and the elderly in less-industrialized areas of the world, ART has also been adopted by developed countries because of the several benefits it offers. ${ }^{18}$

Currently, for ART, the restorative material of choice is high-viscous glass ionomer cement, ${ }^{18}$ which was 
Table 2: Mean values of shear bond strength (SBS) to enamel

\begin{tabular}{|c|c|c|c|c|c|c|c|c|c|}
\hline \multirow{5}{*}{$\begin{array}{l}\bar{\Phi} \\
\stackrel{\Sigma}{\varpi} \\
\check{\varpi} \\
\text { Шे }\end{array}$} & & \multirow[b]{2}{*}{$N$} & \multirow[b]{2}{*}{ Mean } & \multirow[b]{2}{*}{ Std. deviation } & \multirow[b]{2}{*}{ Std. error } & \multicolumn{2}{|c|}{ Interval for mean } & \multirow[b]{2}{*}{ Minimum } & \multirow[b]{2}{*}{ Maximum } \\
\hline & & & & & & Lower bound & Upper bound & & \\
\hline & Zirconomer [Group 1A] & 15 & 5.86 & 0.50 & 0.13 & 5.58 & 6.13 & 5.10 & 7.10 \\
\hline & Ketac $^{\mathrm{TM}}$ molar [Group 2A] & 15 & 6.07 & 0.50 & 0.13 & 5.79 & 6.34 & 5.13 & 6.90 \\
\hline & Fuji IX GP [Group 3A] & 15 & 5.79 & 0.48 & 0.12 & 5.52 & 6.05 & 5.10 & 6.90 \\
\hline
\end{tabular}

Table 3: Intergroup comparison of mean shear bond strengths to enamel

\begin{tabular}{|c|c|c|c|c|c|c|}
\hline \multirow[b]{2}{*}{ Groups } & & \multirow{2}{*}{$\begin{array}{l}\text { Mean } \\
\text { difference } \\
\text { between } \\
\text { groups (MPa) }\end{array}$} & \multirow{2}{*}{$\begin{array}{l}\text { Std. } \\
\text { error }\end{array}$} & \multirow{2}{*}{$\begin{array}{l}\text { Level of } \\
\text { significance }\end{array}$} & \multicolumn{2}{|c|}{ 95\% Confidence interval } \\
\hline & & & & & Lower bound & Upper bound \\
\hline \multirow[t]{2}{*}{$\begin{array}{l}\text { Zirconomer } \\
\text { [Group 1A] }\end{array}$} & $\begin{array}{l}\text { Ketac }^{\mathrm{TM}} \\
\text { Molar [Group 2A] }\end{array}$ & -0.20933 & 0.17971 & 0.480 & -0.6459 & 0.2273 \\
\hline & $\begin{array}{l}\text { Fuji IX GP } \\
\text { [Group 3A] }\end{array}$ & 0.07333 & 0.17971 & 0.912 & -0.3633 & 0.5099 \\
\hline \multirow[t]{2}{*}{$\begin{array}{l}\text { Ketac }^{\mathrm{TM}} \\
\text { molar [Group A] }\end{array}$} & $\begin{array}{l}\text { Zirconomer } \\
\text { [Group 1A] }\end{array}$ & 0.20933 & 0.17971 & 0.480 & -0.2273 & 0.6459 \\
\hline & $\begin{array}{l}\text { Fuji IX GP } \\
\text { [Group 3A] }\end{array}$ & 0.28267 & 0.17971 & 0.268 & -0.1539 & 0.7193 \\
\hline \multirow[t]{2}{*}{$\begin{array}{l}\text { Fuji IX GP } \\
\text { [Group 3A] }\end{array}$} & $\begin{array}{l}\text { Zirconomer } \\
\text { [Group 1A] }\end{array}$ & -0.07333 & 0.17971 & 0.912 & -0.5099 & 0.3633 \\
\hline & $\begin{array}{l}\text { Ketac }^{\mathrm{TM}} \\
\text { Molar [Group 2A] }\end{array}$ & -0.28267 & 0.17971 & 0.268 & -0.7193 & 0.1539 \\
\hline
\end{tabular}

* The mean difference is significant at the 0.05 level

Table 4: Mean values of shear bond strength (SBS) to dentin

\begin{tabular}{|c|c|c|c|c|c|c|c|c|c|}
\hline & & \multirow[b]{2}{*}{$N$} & \multirow[b]{2}{*}{ Mean } & \multirow[b]{2}{*}{ Std. deviation } & \multirow[t]{2}{*}{ Std. error } & \multicolumn{2}{|c|}{ Interval for mean } & \multirow[b]{2}{*}{ Minimum } & \multirow[b]{2}{*}{ Maximum } \\
\hline & & & & & & Lower bound & Upper bound & & \\
\hline \multirow{3}{*}{ 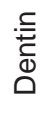 } & Zirconomer [Group 1B] & 15 & 6.23 & 0.41 & 0.11 & 6.00 & 6.46 & 5.50 & 7.20 \\
\hline & Ketac $^{\mathrm{TM}}$ Molar [Group 2B] & 15 & 7.43 & 0.69 & 0.18 & 7.05 & 7.81 & 6.20 & 8.30 \\
\hline & Fuji IX GP [Group 3B] & 15 & 6.04 & 0.32 & 0.08 & 5.86 & 6.22 & 5.61 & 6.90 \\
\hline
\end{tabular}

Table 5: Intergroup comparison of mean shear bond strength to dentin

\begin{tabular}{|c|c|c|c|c|c|c|}
\hline \multirow[b]{2}{*}{ Groups } & & \multirow{2}{*}{$\begin{array}{l}\text { Mean } \\
\text { difference } \\
\text { between } \\
\text { groups (MPa) }\end{array}$} & \multirow{2}{*}{$\begin{array}{l}\text { Std. } \\
\text { error }\end{array}$} & \multirow{2}{*}{$\begin{array}{l}\text { Level of } \\
\text { significance }\end{array}$} & \multicolumn{2}{|c|}{ 95\% Confidence interval } \\
\hline & & & & & Lower bound & Upper bound \\
\hline \multirow[t]{2}{*}{$\begin{array}{l}\text { Zirconomer } \\
\text { [Group 1B] }\end{array}$} & $\begin{array}{l}\text { Ketac }^{\text {TM Molar }} \\
\text { [Group 2B] }\end{array}$ & $-1.19733^{\star}$ & 0.18197 & 0.000 & -1.6394 & 0.7552 \\
\hline & $\begin{array}{l}\text { Fuji IX GP } \\
\text { [Group 3B] }\end{array}$ & 0.19000 & 0.18197 & 0.554 & -0.2521 & 0.6321 \\
\hline \multirow[t]{2}{*}{$\begin{array}{l}\text { Ketac }^{\mathrm{TM}} \text { molar } \\
\text { [Group 2B] }\end{array}$} & $\begin{array}{l}\text { Zirconomer } \\
\text { [Group 1B] }\end{array}$ & $1.19733^{\star}$ & 0.18197 & 0.000 & -0.7552 & 1.6394 \\
\hline & $\begin{array}{l}\text { Fuji IX GP } \\
\text { [Group 3B] }\end{array}$ & $1.38733^{\star}$ & 0.18197 & 0.000 & -0.9452 & 1.8294 \\
\hline \multirow[t]{2}{*}{$\begin{array}{l}\text { Fuji IX GP } \\
\text { [Group 3B] }\end{array}$} & $\begin{array}{l}\text { Zirconomer } \\
\text { [Group 1B] }\end{array}$ & -.19000 & 0.18197 & 0.554 & -0.6321 & 0.2521 \\
\hline & $\begin{array}{l}\text { Ketac }^{\mathrm{TM}} \text { Molar } \\
\text { [Group 2B] }\end{array}$ & $-1.38733^{*}$ & 0.18197 & 0.000 & -1.8294 & -0.9452 \\
\hline
\end{tabular}

* The mean difference is significant at the 0.05 level

Table 6: Intergroup comparison of mode of failure (adhesive, cohesive and mixed) on enamel bond sites

\begin{tabular}{llll}
\hline & \multicolumn{3}{c}{ Enamel subgroup } \\
\cline { 2 - 4 } & Adhesive & Cohesive & Mixed \\
\hline Zirconomer & $66.7 \%$ & $13.3 \%$ & $20.0 \%$ \\
Ketac $^{\mathrm{TM}}$ molar & $60.0 \%$ & $33.3 \%$ & $6.7 \%$ \\
Fuji IX Gp & $66.7 \%$ & $20.0 \%$ & $13.3 \%$ \\
\hline
\end{tabular}

Table 7: Intergroup comparison of mode of failure (adhesive, cohesive and mixed) on dentin bond sites

\begin{tabular}{llll}
\hline & \multicolumn{3}{l}{ Dentin subgroup } \\
\cline { 2 - 4 } & Adhesive & Cohesive & Mixed \\
\hline Zirconomer & $33.3 \%$ & $46.7 \%$ & $20.0 \%$ \\
Ketac $^{\mathrm{TM}}$ molar & $60.0 \%$ & $33.3 \%$ & $6.7 \%$ \\
Fuji IX Gp & $53.3 \%$ & $40.0 \%$ & $6.7 \%$ \\
\hline
\end{tabular}


Table 8: Mean values of flexural strength of zirconomer, Ketac ${ }^{\top M}$ Molar and Fuji IX GP

\begin{tabular}{|c|c|c|c|c|c|c|c|}
\hline \multirow{2}{*}{\multicolumn{3}{|c|}{ Dependent variable }} & \multirow{2}{*}{$\begin{array}{l}\text { Mean } \\
\text { difference } \\
(I-J)\end{array}$} & \multirow{2}{*}{$\begin{array}{l}\text { Std. } \\
\text { error }\end{array}$} & \multirow{2}{*}{$\begin{array}{l}\text { Level of } \\
\text { significance }\end{array}$} & \multicolumn{2}{|c|}{ 95\% Confidence interval } \\
\hline & & & & & & Lower bound & Upper bound \\
\hline \multirow{6}{*}{$\begin{array}{l}\text { Flexural } \\
\text { strength }\end{array}$} & Zirconomer & Ketac $^{\text {TM }}$ molar & $-10.21667^{*}$ & 3.91367 & 0.33 & -19.7249 & 0.7084 \\
\hline & & Fuji IX GP & 5.73000 & 3.91367 & 0.318 & -3.7782 & 15.2382 \\
\hline & $\begin{array}{l}\text { Ketac }^{\mathrm{TM}} \\
\text { molar }\end{array}$ & Zirconomer & $10.21667^{*}$ & 3.91367 & 0.33 & -0.7084 & 19.7249 \\
\hline & & Fuji IX GP & $15.94667^{*}$ & 3.91367 & 0.001 & -6.4384 & 25.4549 \\
\hline & Fuji IX GP & Zirconomer & -5.73000 & 3.91367 & 0.318 & -15.2382 & 3.7782 \\
\hline & & $\begin{array}{l}\text { Ketac }^{\mathrm{TM}} \\
\text { molar }\end{array}$ & $-15.94667^{\star}$ & 3.91367 & 0.001 & -25.4549 & -6.4384 \\
\hline$p$-value ** & \multicolumn{7}{|c|}{${ }^{* *}$ Highly Significant at $p \leq .01$} \\
\hline p-value * & \multirow{2}{*}{\multicolumn{7}{|c|}{ * Significant at $0.01<p \leq .05$}} \\
\hline p-value \# & & \multicolumn{6}{|c|}{ \# No Significant at $p>.05$} \\
\hline
\end{tabular}

designed as an alternative to silver amalgam for posterior restorations. ${ }^{19}$

Examples of high viscosity glass ionomer cement are Fuji IX GP (GC America) and Ketac ${ }^{\mathrm{TM}}$ Molar (3M ESPE). According to the manufacturers of these materials, the relatively higher viscosity is due to the addition of polyacrylic acid to the powder and finer grain-size distribution. ${ }^{20}$ The glass ionomers mainly used for ART restorations have high powder: liquid ratios, and, therefore, higher compressive strengths. These high powder-liquid ratio glassionomers provide a condensable feel and are especially recommended for the Atraumatic restorative treatment introduced by the World Health Organization for use in developing countries. ${ }^{21}$

Zirconomer (White Amalgam) has been developed to exhibit strength similar to silver amalgam, through a rigorous manufacturing technique. The glass component of this high-strength GI undergoes finely controlled micro ionization to achieve optimum particle size and characteristics.

In the present study $\mathrm{Ketac}^{\mathrm{TM}}$ molar $(\mathrm{KM})$ showed the highest shear bond strength to enamel $(6.07 \pm 0.50 \mathrm{MPa})$ and dentin $(7.43 \pm 0.69 \mathrm{MPa})$ which were comparable to the results of the study conducted by Carvalho et al. (enamel bond strength $6.4 \pm 1.4$; dentin bond strength $7.6 \pm 1.5) .^{9}$

Yesilyurt et al. ${ }^{22}$ reported a mean SBS value of $3.4 \pm 0.7$ $\mathrm{MPa}$ for $\mathrm{Ketac}^{\mathrm{TM}}$ molar to dentin which was much lower than in the present study.

Fuji IX GP extra (FJ) also showed results (enamel bond strength $5.79 \pm 0.48 \mathrm{MPa}$; dentin bond strength $6.04 \pm 0.32$ $\mathrm{MPa}$ ), which were comparable to the results of the study by Carvalho et al. (enamel bond strength $5.9 \pm 1.5$; dentin bond strength $6.0 \pm 1.9){ }^{9}$

The bond strength of Fuji IX GP extra to dentin in the present study $(6.04 \pm 0.32 \mathrm{MPa})$ was also comparable of a study conducted by Raju et al., ${ }^{12}$ where the dentine bond strength of GIC Fuji IX was $6.41 \pm 2.44 \mathrm{MPa}$. The results of the study by Omrani et al. ${ }^{23}$ showed a mean value of 5.91 MPa for Fuji IX of SBS to dentin which was comparable with the results of the present study.

Zirconomer showed $5.86 \pm 0.50 \mathrm{MPa}$ SBS to enamel, and $6.43 \pm 0.41 \mathrm{MPa}$ SBS to dentine. A thorough search of print and electronic databases revealed no other published study evaluating the SBS of Zirconomer to human enamel and dentin. Hence, the results of the present study could not be compared, and therefore provide important information about the bond strength of Zirconomer.

In accordance with the previous studies, ${ }^{14,24,25}$ the fracture sites after debonding were analyzed using stereomicroscope under $10 \mathrm{x}$ magnifications in the present study. A predominance of the adhesive mode of failure was seen for Zirconomer for enamel surfaces, while a greater percentage of the cohesive mode of failure was observed for the dentin surfaces. KM and FJ showed predominantly adhesive failure for both the enamel and dentine bond surfaces/sites. The results of the present study are contrary to the results of studies conducted by Lucas et al. ${ }^{26}$ Yap et al. ${ }^{27}$ who reported a more significant percentage of the cohesive mode of failure for GIC on dentin surfaces. The authors implied that as the interfacial strength of the cement-tooth bond was higher than the inherent strength of the material, a greater percentage of the cohesive mode of failure would be encountered.

The bond strength tests for GICs cannot always express the interface bond strength as they report cohesive failures within the material, limiting the results to material strength. ${ }^{28}$

Another factor that could have influenced the bond strength is the conditioning agent applied on the dental substrate. ${ }^{29}$ In the present study, the liquid component of the GIC was used to condition the tooth surface in accordance with the protocol used by Pereira et al., ${ }^{29}$ Holmgren et al. ${ }^{30}$ Koenraads et al. ${ }^{31}$ 
Powder/liquid $(\mathrm{P} / \mathrm{L})$ ratio is one of the factors indicated in altering the mechanical properties of GICs; the higher the amount of powder, the higher the mechanical properties (Beher et al., Yap et al.). ${ }^{32,33}$ Due to the vast disparity of $\mathrm{P} / \mathrm{L}$ ratios and the results reported, it is challenging to make a definite conclusion concerning the ideal $\mathrm{P} / \mathrm{L}$ ratio, as surmised by Torabzadeh et al. ${ }^{34}$ in their study for evaluating the effect of varying the powder/liquid (P/L) ratio on the SBS and FS of glass ionomer cements.

As the present study followed the protocols of ART, scoop method was used for dispensing powder and liquid powder and liquid.

No attempt was made to correlate the shear bond strength and the mode of failure, as a previous study by El Wakeel et al..$^{35}$ indicated that there is no relationship between the two.

Flexural strength and diametral tensile strength tests are used to assess the mechanical properties of materials, including glass ionomer cement. ${ }^{10}$ The measurement of flexural strength offered the best practical and reliable estimate of tensile strength, ${ }^{36}$ in the present study the strength of the restorative materials was assessed by a flexural test.

The results of the flexural strength measurements for the present study showed that Ketac molar demonstrated the highest strength $(62.6 \pm 13.59 \mathrm{MPa})$ when compared with Zirconomer $(52.46 \pm 10.68 \mathrm{MPa})$ and Fuji IX GP Extra $(46.73 \pm 6.77 \mathrm{MPa})$. The values demonstrated by Ketac molar and Fuji IX GP extra in the present study were higher but almost comparable to the results of the study conducted by Peez et al., ${ }^{4}$ where the FS for Ketac Molar, after 24 hours, was $51 \pm 5 \mathrm{MPa}$ and for Fuji IX was $42 \pm 4 \mathrm{MPa}$.

In a study by Bonifaccio et al. ${ }^{3} \mathrm{FS}$ of Ketac molar and Fuji IX demonstrated a mean FS value of $34.5 \pm 7.2 \mathrm{MPa}$ and $33.3 \pm 6.1 \mathrm{MPa}$ respectively for Ketac molar for Fuji IX which was lower than the present study.

Few studies have evaluated the FS of Zirconomer. A thorough search of the online and print literature was done which showed a study conducted by Hambire et al. ${ }^{7}$ demonstrating a mean FS value of Zirconomer $10.27 \pm$ $0.5 \mathrm{MPa}$, which was much lower than the results of the present study (52.46 $\pm 10.68 \mathrm{MPa})$.

The differences in the findings of the present study and others could be attributed to critical differences in study protocols. In the present study, the specimens were immediately immersed in distilled water once the material was set. Also, intentionally, no protective coating was applied to the specimens.

Flexural strength studies are very technique sensitive and any irregularities (cracks, porosities) in the specimens could result in lower flexural strengths. The following factors may play a critical role fabrication: using rigid split and sealed molds, applying a coating on the specimens, and polishing procedures. ${ }^{10}$

As there are different approaches to specimen fabrication, this factor may be significant when comparing studies. Future research is needed to evaluate the effects of the protective coating and delayed polishing on flexural strength values of GIC. Therefore, even though the data in this study may not correspond to values published in the scientific literature, it is still useful for providing new information about the flexural strengths of newer GICs.

Majority of in vitro studies such as tensile, compression, shear or flexural strength, are monotonic tests, which cannot simulate fatigue that occurs in the mouth. Therefore, further testing which incorporates subjecting the specimens to fatigue is recommended for better clinical relevance.

Another limitation of the present study is that the specimens were not subjected to thermocycling, which is done to simulate clinical conditions. Future studies may be conducted to examine the effect of the same

The present study employed the macro-shear testing (which is also one of the limitations of the study) methodology which is the most commonly employed method for testing SBS. However, recent literature has begun to focus on micro-shear testing methodology, where the bonded cross-sectional area is less than $1 \mathrm{~mm}^{2}$, which is said to be more reliable and can be used to further assess the shear bond strength of the materials tested in the present study.

\section{CONCLUSION}

Based on the results and within the limitations of the present study, Ketac ${ }^{\mathrm{TM}}$ molar showed the best performance among all the tested materials. Zirconia reinforced glass ionomer restorative material Zirconomer had comparable results, Zirconomer, had comparable results with that of Fuji IX GP Extra. Hence, Zirconomer can be considered as an alternative to conventional GICs for application in ART, though further studies are required to prove its performance in a clinical scenario.

\section{CLINICAL SIGNIFICANCE}

The results of the present study showed that KM demonstrated the best performance among the tested materials, while while Zirconomer and FJ were comparable. While further studies are required to prove its performance in a clinical scenario, Zirconomer can be considered as an alternative to conventional GICs for application in ART. 


\section{ACKNOWLEDGMENT}

Authors are grateful to the authorities of Central Silk Technology and Research Institute and to the Department of Prosthodontics, Department of Microbiology and Pathology, VIDS and RC, for their constant support.

\section{REFERENCES}

1. Berg JH. Glass Ionomer cements. Pediatr Dent. 2002;24(5):430438.

2. Topbasi B, Öveçoglu ML, Turkmen C. Flexural strength and fracture surface characterization of glass-ionomer cements stored in water. OHDMBSC 2003;2(4):18-25.

3. Bonifacio CC, Kleverlaan CJ, Raggio DP, Werner A, Carvalho RC, van Amerongen WE. Physical-mechanical properties of glass ionomer cements indicated for atraumatic restorative treatment. Aust Dent J 2009;54(3):233-237.

4. Peez R, Frank S. The physical-mechanical performance of the new Ketac Molar Easymix compared to commercially available glass ionomer restoratives. J Dent 2006;34(8):582-587.

5. Somani R, Jaidka S, Singh DJ, Sibal GK. Comparative evaluation of shear bond strength of various glass ionomer cements to dentin of primary teeth: An in vitro Study. Int J Clin Pediatr Dent 2016;9(3):192-196.

6. Chalissery VP, Marwah N, Almuhaiza M, AlZailai AM, Chalisserry EP, Bhandi SH, et al. Study of the mechanical properties of the novel zirconia-reinforced glass ionomer cement. J Contemp Dent Pract 2016;17(5):394-398.

7. Patil KM, Hambire UV. Comparative Evaluation of Compressive, Flexural Strength and Micro Hardness of Different Dental Materials. IJSRD 2016;4(4):444-448.

8. International Standard Organisation. ISO/TS11405:2015. Dentistry-Testing of adhesion to tooth structure. Geneva. ISO/TS:2015. Available from: http://www.iso.org/iso/ prods-services/ISOstore/store.html

9. Carvalho TS, van Amerongen WE, de Gee A, Bönecker M, Sampaio FC. Shear bond strengths of three glass ionomer cements to enamel and dentine. Med Oral Patol Oral Cir Bucal. 2011 May 1;16(3):e406-410.

10. Chander K. Effects of aging on dentin bonding and mechanical properties of restorative glass ionomer cements. 2011. Available from: https://open.library.ubc.ca/cIRcle/collections/ubctheses/24/items/1.0308659

11. Shebl EA., Etman WM., Genaid ThM, Shalaby ME. Durability of bond strength of glass ionomers to enamel. Tanta Dent J 2015;12:16-27.

12. RajuVG,VenumbakaNR,MungaraJ,VijayakumarP,RajendranS, Elangovan A. Comparative evaluation of shear bond strength and microleakage of tricalcium silicate-based restorative material and radioopaque posterior glass ionomer restorative cement in primary and permanent teeth: An in vitro study. J Indian Soc Pedod Prev Dent 2014;32:304-310.

13. Gordan VV, Boyer D, Soderholm KJ. Enamel and dentine shear bond strength of two resin modified glass ionomers and two resin based adhesives. J Dent 1998;26:497-503.

14. Poggio C, Beltrami R, Scribante A, Colombo M, Lombardini $M$. Effects of dentin surface treatments on shear bond strength of glass-ionomer cements. Ann Stomatol(Roma). 2014 Mar 31;5(1):15-22.

15. Nagwa Mohamed AlyKhattab and Ola Moustafa Omar Papain-Based Gel for Chemo-Mechanical CariesRemoval:
Influence on Microleakage and Microshear Bond Strength of Esthetic Restorative Materials. Journal of American Science 2012;8(3): 391-399.

16. ISO/Final Draft International Standard 4049:2000(E): Dentistry-Polymer-based filling, restorative and luting materials.Geneva, Switzerland, ISO Copyright Office, 2000. Available from: https://www.iso.org/standard/23041.html

17. Piwowarczyk A, Ottl P, Lauer HW, Buchler A. Laboratory Strength of Glass Ionomer Cement, Compomers, and Resin Composites. J Prosthodont 2002;11:86-91.

18. Raggio DP, Hesse D, Lenzi TL, Guglielmi CA, Braga MM. Is Atraumatic restorative treatment an option for restoring occlusoproximal caries lesions in primary teeth? A systematic review and meta-analysis. Int J Paediatr Dent. 2013 Nov;23(6):435-443.

19. Hilgert LA, de Amorim R, Leal SC, Mulder J, Creugers NH, Frencken JE. Is high-viscosity glass-ionomer-cement a successor to amalgam for treating primary molars? Dental Materials 2014;30(10):1172-1178.

20. NagarajaUpadhya P, Kishore G. Glass Ionomer Cement The Different Generations. 2005 Jan;18(2);158-165. Available from: http://medind.nic.in/taa/t05/i2/taat05i2p158.pdf

21. Yap AU, Pek YS, Cheang P. Physico-mechanical properties of a fast-set highly viscous GIC restorative. J Oral Rehabil. 2003 Jan;30(1):1-8.

22. Yesilyurt C, Bulucu B, Sezen 0, Bulut G, Celik D. Bond strengths of two conventional glass-ionomer cements to irradiated and non-irradiated dentin. Dent Mater J 2008; 27(5):695-701.

23. Omrani LR, Sabouri P, Abbasi A, Ahmadi E, Ghavam M. Shear bond strength of two types of glass ionomer to bleached dentin: effect of delayed bonding and antioxidant agent. TODENTTJ 2016;10:720-727.

24. Nujella BP, Choudary MT, Reddy SP, Kumar MK, Gopal T. Comparison of shear bond strength of aesthetic restorative materials. Contemp Clin Dent. 2012 Jan;3(1):22-26.

25. Khattab NM, Omar OM. Papain-Based Gel for ChemoMechanical CariesRemoval: Influence on Microleakage and Microshear Bond Strength of Esthetic Restorative Materials. Journal of American Science 2012;8(3):391-399.

26. E. Lucas M, Arita K, Nishino M. Toughness, bonding and fluoride-release properties of Hydroxyapatite-added glass ionomer cement. Biomaterials 2003;24:3787-3794.

27. Yap AU, Pek YS, Kumar RA, Cheang P, Khor KA. Experimental studies on a new bioactive material: HAIonomer cements. Biomaterials. 2002 Feb;23(3):955-962.

28. Bonifácio, CC. The ART of GIC proximal restorations in primary teeth. 2012. Available from: https://pure.uva.nl/ ws/files/1871468/146155_thesis.pdf

29. Garcia Pereira LC, PessuttiNunes MC, Palma Dibb RC, M. Powers J, François Roulet J, de Lima Navarro MF. Mechanical Properties and Bond Strength of Glass-ionomer Cements. J Adhes Dent 2002;4:73-80.

30. Holmgren CJ, Roux D, Doméjean S. Minimal intervention dentistry: part 5. Atraumatic restorative treatment (ART) - a minimum intervention and minimally invasive approach for the management of dental caries. BDJ 2013;214:11-18.

31. Koenraads H, Van der Kroon G, Frencken JE. Compressive strength of two newly developed glass-ionomer materials for use with the Atraumatic Restorative Treatment (ART) approach in class II cavities. Dent Mater. 2009 Apr;25(4):551-556. 
32. Beher M, Rosentritt M, Loher H, Handel G. Effect of variation from recommended powder/liquid ratio on some properties of resin-modified cements. Acta Odontol Scand. 2006;64:214-220.

33. Yap AUJ, Mudambi S, Chew CL, Neo JCL. Mechanical properties of improved visible light-cured resin-modified glass ionomer cement. Oper Dent. 2001;26:295-301.

34. Torabzadeh H, Ghasemi A, Shakeri S, Baghban AA, Razmavar S. Effect of powder/liquid ratio of glass ionomer cements on flexural and shear bond strengths to dentin. Braz J Oral Sci. 2011 Jul-Sep;10(3):204-207.

35. El Wakeel AM, Elkassas DW, Yousry MM. Bonding of contemporary glass ionomer cements to different tooth substrates; microshear bond strength and scanning electron microscope study. Eur J Dent 2015;9:176-182.

36. Prosser HJ, Powis DR, Wilson AD. Glass-ionomer cements of improved flexural strength. J Dent Res 1986;65:146-148. 